\title{
Evaluation of the Antioxidant Activity and Dosage of Polyphenols in Aqueous, Hydroethanolic and Hexane Extracts of the Bark of Spathodea campanulata P. Beauv. (Bignoniaceae)
}

\author{
Koulai Diane $^{1 *}$, Yeo Sounta Oumar ${ }^{1}$, Doumbia Idrissa ${ }^{1,2}$, \\ Yapi Houphouet Felix ${ }^{2}$, N'guessan Jean David ${ }^{2}$ and Djaman Allico Joseph ${ }^{2,3}$
}

${ }^{1}$ Food and Bioproducts Processes Laboratory, Agronomic, Forestry and Environmental Engineering Department, University of Man, PO Box 20 Man, Ivory Coast, Côte d'Ivoire

${ }^{2}$ Biochemical Pharmacodynamic Laboratory, Biosciences Department, Felix HouphouetBoigny University, PO Box 582, Abidjan 22, Ivory Coast, Côte d'Ivoire

${ }^{3}$ Biochemical Laboratory of Pasteur Institute of Ivory Coast, PO Box 490, Abidjan 01, Ivory Coast, Côte d'Ivoire

*Corresponding author

\section{A B S T R A C T}

The present study focused on the evaluation of the antioxidant properties and the determination of total phenols and flavonoids Spathodea campanulata P. Beauv by spectrophotometry. Quantitative analyzes of total phenols and

Keywords

Total polyphenols, antioxidant activity, Spathodea campanulata

Article Info

Accepted:

12 June 2021

Available Online:

10 July 2021 flavonoids were determined from the linear regression equation of the calibration curve, that is plotted using gallic acid and quercetin respectively as standard. The highest content of phenols was measured in the hydro-ethanolic extract, with a value equal to $10.17 \mathrm{mgGAE} / \mathrm{g}$ DE. Likewise, the determination of the flavonoids revealed that the hydroethanolic extract contains a maximum of flavonoids, with a level of $22.43 \mathrm{mg}$ EQ / g DE. The antioxidant properties were evaluated by two tests, namely the diphenyl-picryl-hydrazyl radical scavenging test (DPPH) and the reducing power test (FRAP) in comparison with ascorbic acid and BHT respectively used as reference molecules. The results obtained show that the antioxidant activity of the hydroethanolic extract is greater with the two tests than those of the aqueous and hexane extracts.

\section{Introduction}

The use of synthetic antioxidant molecules is currently being questioned because of the potential toxicological risks they present.
Today, new molecules of plant origin (natural antioxidant) are being sought (Suhaj, 2006). The study of plant chemistry is still relevant today because the plant kingdom today represents an important and unavoidable 
source in the discovery of a huge variety of new bioactive molecules (Harrar, 2012). Several scientific studies have shown that different secondary metabolites of these plants have been isolated and are used as therapeutic molecules (Huang et al., 2005). Among these metabolites are the phenolic compounds which are gaining in importance thanks to their beneficial effects on health. They are also participating in the protection of plants against various attacks (Bruneton, 1999). The Ivorian flora is characterized by numerous medicinal plants which is the single most used element, especially in rural areas, to solve public health problems. According to the National Program for the Promotion of Traditional Medicine of Côte d'Ivoire, 1421 species of medicinal plants involved in traditional medicine and allowing patient care, have been identified to date by Ivorian researchers.

Also Spathodea campanulata, a plant with multiple therapeutic virtues is used in traditional medicine. Stem bark preparations are used for enemas, to treat fungal skin diseases, herpes, stomach aches, diarrhea; antimalarial activities have also been observed in stem bark extracts (Jardim et al., 2003; Niyonzima et al., 1999; Rangasamy Dhanabalan et al., 2008). Several phytochemical studies have been performed with different parts of Spathodea campanulata, namely the bark of the stem, the leaves, the flowers and the fruits (Amusan et al., 1996).

The leaves provided spathodol, caffeic acid, other phenolic acids and flavonoids showed the presence of anthocyanins in the flowers of Spathodeae campanulata (El-Hela, 2001a; ElHela, 2001b; Banerjee et DE 2001). This work is concerned with the evaluation of the antioxidant activity and the quantitative dosage of the phenolic compounds of the aqueous, hydroethanolic and hexane extracts of the bark of Spathodea campanulata.

\section{Materials and Methods}

\section{Plant Material}

The plant material is composed of the bark of Spathodea campanulata. These barks were cut up and dried out of direct sunlight at room temperature $\left(25-30^{\circ} \mathrm{C}\right)$ for four weeks, before being reduced to a fine powder by grinding using a mechanical grinder. Then stored in glass bottles protected from light and humidity for their use.

\section{Chemical material}

In order to extract the compounds, we used $70^{\circ}$ ethanol and distilled water. For evaluating the antioxidant properties, Folin-Ciocalteur reagent, methanol, sodium carbonate solution, gallic acid, potassium acetate, sodium phosphate, potassium ferric cyanide, trichloroacetic acid, Ferric chloride, aluminum chloride and 2,2-diphenyl-picrylhydrazyl (DPPH) and butylhydroxytoluene (BHT) were used.

\section{Methods of preparing extracts}

The preparation of the total aqueous, hydroethanolic and hexane extracts was carried out according to the method of Zirihi et al., (2003), by homogenization using a mixer. The extracts were obtained from $100 \mathrm{~g}$ of powder and $1 \mathrm{~L}$ of solvent which was homogenized in a mixer. After $15 \mathrm{~min}$ of homogenization, the obtained homogenate was collected in a square of white (clean) tissue and pressed by hand using strong pressure applications. The collected solution was filtered twice through cotton wool and then through Whatman $3 \mathrm{~mm}$ filter paper.

Aliquots of the filtrate were placed in a dryer at $40^{\circ} \mathrm{C}$ for 48 hours for the aqueous extract and at $50{ }^{\circ} \mathrm{C}$ for 24 hours for the hydroethanolic and hexane extract. 
Evaluation of the content of phenolic compounds

\section{Determination of total phenols}

The total phenol content was determined in the extracts of Spathodea campanulata according to the method described by Mc Donald et al., (2001) using the Folin-ciocalteu reagent. To $0.5 \mathrm{~mL}$ of the extract, $(0.1 \mathrm{~g} /$ $\mathrm{mL}$ ), $5 \mathrm{~mL}$ of the Folin-ciocalteu reagent which is diluted to $1 / 10$ th with distilled water and $4 \mathrm{~mL}$ of sodium carbonate $(1 \mathrm{M})$ are respectively added.

After $15 \mathrm{~min}$ of incubation at room temperature, the optical density is measured with a spectrophotometer at $765 \mathrm{~nm}$. Gallic acid prepared in a (50/50, v / v) methanol / water solvent mixture is used as a standard at concentrations ranging from 0 to $250 \mathrm{mg} / \mathrm{L}$. The total phenol content of the various extracts is expressed in terms of gallic acid equivalents per gram of extract (mg GAE / g).

\section{Dosage of total flavonoids}

The quantification of flavonoids was done by a colorimetric method based on the formation between aluminum chloride and the oxygen atoms present on the 4 and 5 carbons of the flavonoids (Lagnika, 2005). The protocol used is based on that described by (Meda et al., 2005) with some modifications. $0.5 \mathrm{~mL}$ of distilled water, $0.5 \mathrm{~mL}$ of aluminum chloride, $0.5 \mathrm{~mL}$ of potassium acetate and $2 \mathrm{~mL}$ of distilled water are successively added to a volume of $0.5 \mathrm{~mL}$ of methanolic extracts.

The resulting solution is left to stand for 30 min in the dark and the optical density is read at $415 \mathrm{~nm}$ against the blank. A calibration range is carried out under the same conditions as the test using a quercetin stock solution at $0.01 \mathrm{mg} / \mathrm{mL}$ to determine the flavonoid content of the sample. The flavonoid contents of the extracts are expressed in $\mathrm{mg}$ quercetin equivalents per gram of extract (mg EQ / $g$ of extract).

In Vitro evaluation of the antioxidant activity of aqueous, hydroethanolic and hexane extracts of Spathodea campanulata

\section{Free Radical Scavenging Activity}

Hydrogen atom or electron donating abilities of the compounds were measured from the bleaching of the purple-colored methanol solution of 2,2-diphenyl-1-picryl hydrazyl (DPPH). This spectrophotometric assay uses the stable free radical, DPPH as a reagent (Parejo et al., 2000).

Different concentrations of each extract were added, at an equal volume, to methanolic solution of DPPH $(100 \mu \mathrm{L})$. After $30 \mathrm{~min}$ at room temperature, the absorbance was recorded at $517 \mathrm{~nm}$. Test was repeated for three times. Vitamin $\mathrm{C}$ was used as standard control. The DPPH radical scavenging effect was calculated as inhibition of percentage (I\%) using the following formula: $\mathrm{I} \%=(\mathrm{A}$ Blank-A Sample / A Blank); A blank is the absorbance of the control reaction (containing all reagents except the test compound) and $\mathrm{A}$ sample is the absorbance of the test compound.

The values of inhibition were calculated for concentrations of the extract. IC50 values denote the concentration of sample, which is required to scavenge $50 \%$ of DPPH free radicals. Chemicals Reagents All chemicals used were of analytical grade. Methanol, aluminum chloride, potassium acetate, 2,2Diphenyl-1-picrylhydrazyl (DPPH), ferrous chloride, ferrozine, potassium ferricyanide, Folin-ciocalteu reagent, standards such as Ascorbic acid, ethylene diaminetetra acetic acid (EDTA), gallic acid, quercetin all from Sigma Chemicals Co. (St. Louis, MO, USA). 


\section{Reducing power measurement (FRAP)}

\section{Principle}

The FRAP method is based on the reduction of ferric ion $(\mathrm{Fe} 3+)$ to ferrous ion $(\mathrm{Fe} 2+)$. This method evaluates the reducing power of the compounds. The presence of reducing agents (HA) in plant extracts causes the reduction of $\mathrm{Fe} 3+/$ ferricyanide complex to the ferrous form.

Therefore, $\mathrm{Fe} 2+$ can be evaluated by measuring and monitoring the increase in the density of the cyan blue color in the reaction medium at $700 \mathrm{~nm}$ (Chung et al., 2002).This method measures the reducing power of antioxidants present in a mixture by their ability to reduce ferric tripyridyltriazine ( $\mathrm{Fe} 3$ $+-\mathrm{TPTZ})$ to ferrous ion $(\mathrm{Fe} 2+-\mathrm{TPTZ})$ at acidic $\mathrm{pH}$.

According to the method described by Yildirim et al., (2001). $2 \mathrm{~mL}$ of extracts were mixed with $2.5 \mathrm{~mL}$ of sodium phosphate buffer solution $(0.2 \mathrm{M} ; \mathrm{pH} 6.6)$ and $2.5 \mathrm{~mL}$ of potassium ferric cyanide (1\%).

The mixture was incubated at $50{ }^{\circ} \mathrm{C}$ for 30 min, then $2.5 \mathrm{~mL}$ of trichloroacetic acid (10\%) was added to the mixture and the resulting solution was centrifuged at $2000 \mathrm{~g}$ for $10 \mathrm{~min}$. To a volume of $2.5 \mathrm{~mL}$ of the supernatant is added respectively $2.5 \mathrm{~mL}$ of deionized water and $0.5 \mathrm{~mL}$ of ferric chloride, then the absorbance was measured with a spectrophotometer at $700 \mathrm{~nm}$.

\section{Statistical Analysis}

The statistical analysis was performed by Graph Pad Prism 6 statistical software. Results are expressed as mean \pm SD and analyzed by ANOVA and Tukey tests with univariate rate determination of significance with $\mathrm{P} \leq 0.001$ considered statistically significant.

\section{Results and Discussion}

Determination of total phenolic compounds present in aqueous, hydroethanolic and hexane extracts of Spathodea campanulata

The quantitative analyzes of total phenols and total flavonoids were determined from the equation of the linear regression of the calibration curve $\mathrm{y}=8.1544 \mathrm{x}+00 ; \mathrm{R} 2=$ 0.9977 and $\mathrm{y}=1.357 \mathrm{x}-0.0181 ; \mathrm{R} 2=0.9976$, plotted using gallic acid and quercetin as standard respectively. The values obtained are expressed in $\mathrm{mg} \mathrm{GAE} / \mathrm{g} \mathrm{DE}$ and in $\mathrm{mg} \mathrm{EA} / \mathrm{g}$ DE (Figures 1 and 2).

For this study, three solvents were used with the powder and the bark of Spathodea campanulata, namely distilled water, hydroethanol and hexane, which made it possible to obtain three extracts: the aqueous extract, the hydroethanolic extract and the hexane extract.

First of all, as for the determination of total phenols, it can be observed a blue color after adding Folin-Ciocalteu reagent, which confirms the presence of total phenols in the various extracts of $S$. campanulata. The highest content of phenols was found in the hydro-ethanolic extract, with a value equal to $10.17 \mathrm{mg}$ GAE / g DE, followed by the hexane and aqueous extracts respectively 7.64 and $4.44 \mathrm{mg} \mathrm{GAE} / \mathrm{g}$ DE. To our knowledge, no quantitative studies have been carried out on extracts from the bark of the plant, however Umenwa et al., (2017) in Nigeria, have noted the presence of polyphenols in the methanolic fractions of the leaves of $\mathrm{S}$. campanulata. This is because the contents of phenolic compounds vary qualitatively and quantitatively in the same plant as well as from one plant to another, and this can be explained by the origin of the plant, by the method of extraction (Djeridane et al., 2013). The polyphenolic profile of plant extracts can vary under the influence of several factors, 
among which are the variety, the geographical location, the climatic conditions of growth, and the stage of maturity of the plant according to Anusuya et Manian, (2013), likewise, the different diseases that can affect the plant (Perron et Brumaghim, 2009).

The highest content of phenols was measured in the hydro-ethanolic extract, hexane and aqueous extracts. The current results are in agreement with those of Conde et al., (2009)who have shown that the polyphenolic profile of extracts from the same plant can vary according to the type and polarity of the extraction solvent as well as the analysis techniques and the substrate employed(Zhao et al., 2007). According to Alonso et al., (2007), light increases the biosynthesis of phenolic compounds that accumulate in plant cells. In addition, the extraction time factor is very important, since a long time increases the possibility of oxidation of phenolic compounds, according to (Naczk et Shahbi, 2004). In addition, undesirable reactions such as enzymatic oxidation and polymerization could be fostered by a prolonged extraction time.

Furthermore, the quantitative estimate of total flavonoids by the aluminum trichloride method shows that the hydroethanolic extract contains a maximum of flavonoids, with a rate of $22.43 \mathrm{mg}$ EQ / $\mathrm{g}$ DE compared to the hexane and aqueous extracts. Results for total flavonoid content vary widely amongst different extracts.

The concentration of flavonoids in plant extracts depends on the polarity of the solvents used in the preparation of the extracts (Pedneault et al., 2001). Recent studies have shown that extrinsic factors (such as geographical and climatic factors), genetic factors, but also the degree of maturation of the plant and the shelf life have a strong influence on the content of polyphenols and flavonoids (Fiorucci, 2006). In addition, Katalinic et al., (2010)work confirms our results by indicating that ethanol allows a better extraction of total polyphenols. This largely explains the richness of the hydroethanolic extract of the bark of $S$. campanulata in polyphenols compared to other extracts. It is the same for the content of flavonoids.

In addition, the antioxidant activity of aqueous, hydro-ethanolic and hexane extracts of the bark of Spathodea campanulata was also studied using two methods based on the ability of compounds to scavenge synthetic free radicals (DPPH), generating free radicals, and to test the reducing power of different extracts. In fact, the DPPH test is one of the most widely used tests to determine the antifree radical activity of plant extracts (Laguerre et al., 2007). The results of anti-free radical activity revealed that aqueous, hydro-ethanolic and hexane extracts inhibited DPPH by $40 \%$, $77 \%$ and $60 \%$, respectively. The hydroethanolic extract has good anti-free radical activity with an IC50 of $30.20 \pm 0.40(\mu \mathrm{g} /$ $\mathrm{mL}$ ) close to that of vitamin $\mathrm{C}$ and clearly superior to those of Umenwa et al., 2017who found an IC50 of 178, $46 \mu \mathrm{g} / \mathrm{mL}$ with the hexane fraction of the leaves of $S$. campanulata. Similarly, by observing the results of the iron reducing power test of our various extracts, it is clear that the hydroethanolic extract also has the highest reducing power, this is explained by the high content of phenolic compounds in $S$. campanulata. According to Singh et al., (2006) reductones are compounds with strong reducing power and are able to reduce ferric iron $(\mathrm{Fe} 3+)$, give up electrons and transform active free radicals into stable products. The antioxidant activity of $S$. campanulata extracts. According to the reducing power test, it is revealed that the latter have an important activity. The evaluation of antioxidant activity in vitro has shown that our extracts are able to reduce DPPH free radicals and iron. 
Table.1 Content values of total phenols and flavonoids present in extracts of $S$. campanulata.

\begin{tabular}{|c|c|c|}
\hline Extracts & $\begin{array}{c}\text { Total Phénols } \\
\text { (mg/EAG/g d'ES) }\end{array}$ & $\begin{array}{c}\text { Total Flavonids } \\
\text { (mg EQ/g d'ES) }\end{array}$ \\
\hline EAq & $4,44 \pm 0,07$ & $7,23 \pm 0,13$ \\
\hline EEth & $10,17 \pm 0,49$ & $22,43 \pm 0,55$ \\
\hline EHex & $7,64 \pm 0,45$ & $8,52 \pm 0,62$ \\
\hline
\end{tabular}

EAq: aqueous extract; EEth: hydroethanolic extract; EHex: hexane extract; mg / EAG / g ES: milligram of gallic acid equivalence per gram of dry extract; $\mathbf{m g}$ EG / $\mathbf{g}$ ES: milligram of quercetin equivalence per gram of dry extract.

NB: Each value corresponds to the mean \pm Standard deviation. (Student's test: $* * * p<0.001$ )

Graph.1 Total phenol content of extracts of $S$. campanulata bark (Mean \pm SD of three trials)

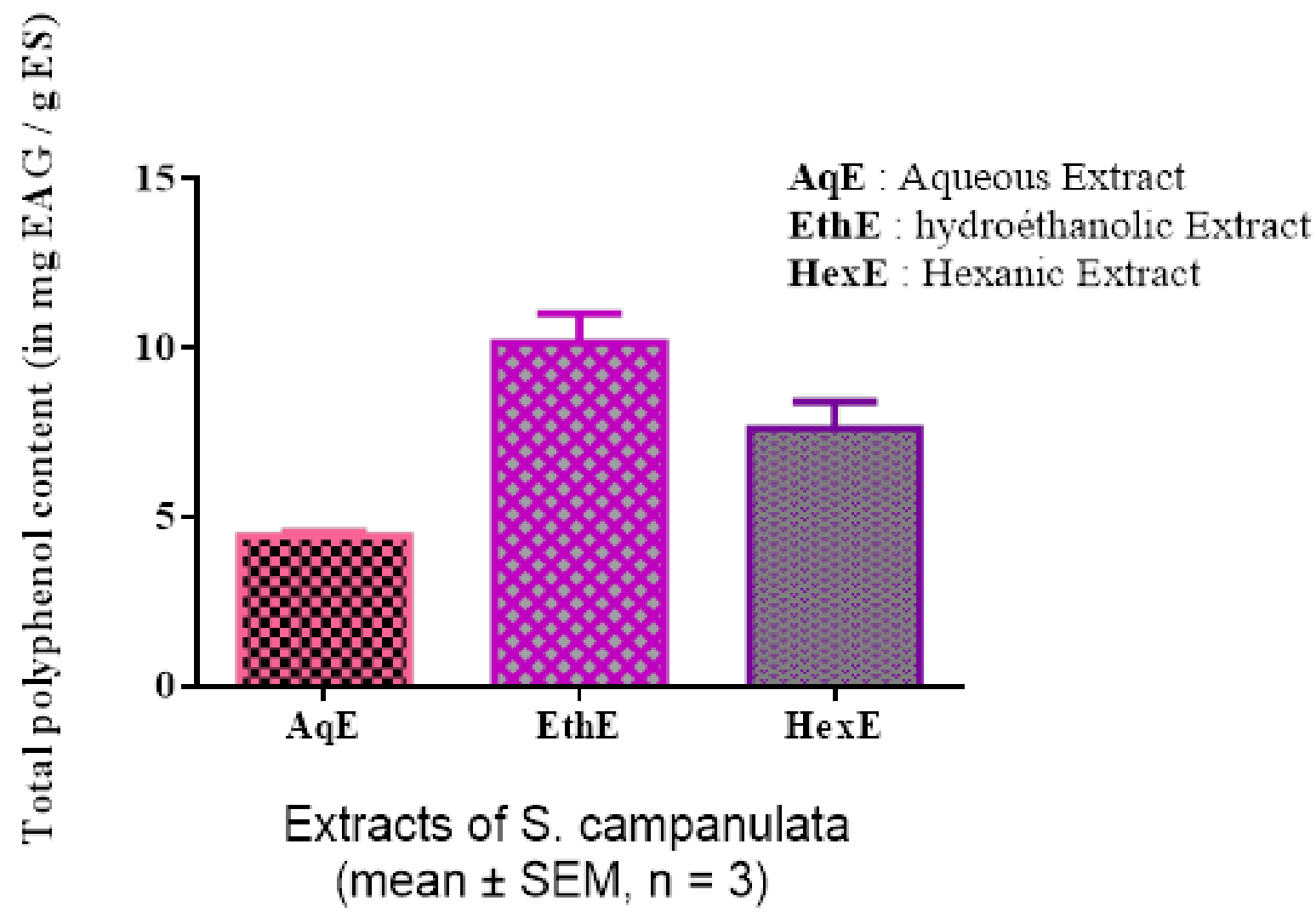


Graph.2 Flavonoids content of extracts of $S$. campanulata bark (Mean \pm SD of three trials)

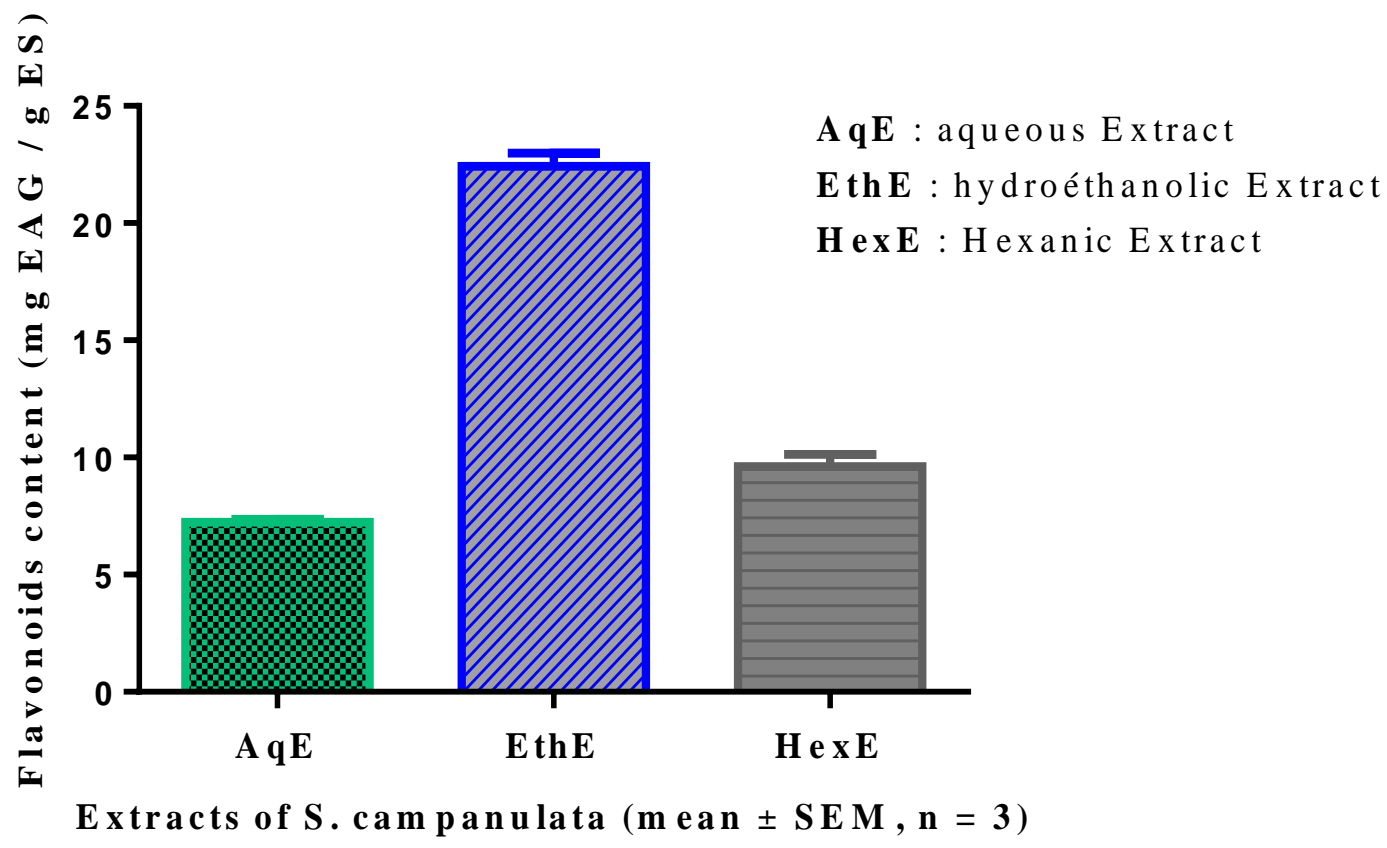

Evaluation of the antioxidant activity of aqueous and ethanolic extracts of Spathodeae campanulata in vitro

Graph.3 Evolution of the anti-free radical activity of extracts of Spathodea campanulata and vitamin $\mathrm{C}$ according to the concentration

\section{Measurement of anti-radical activity}

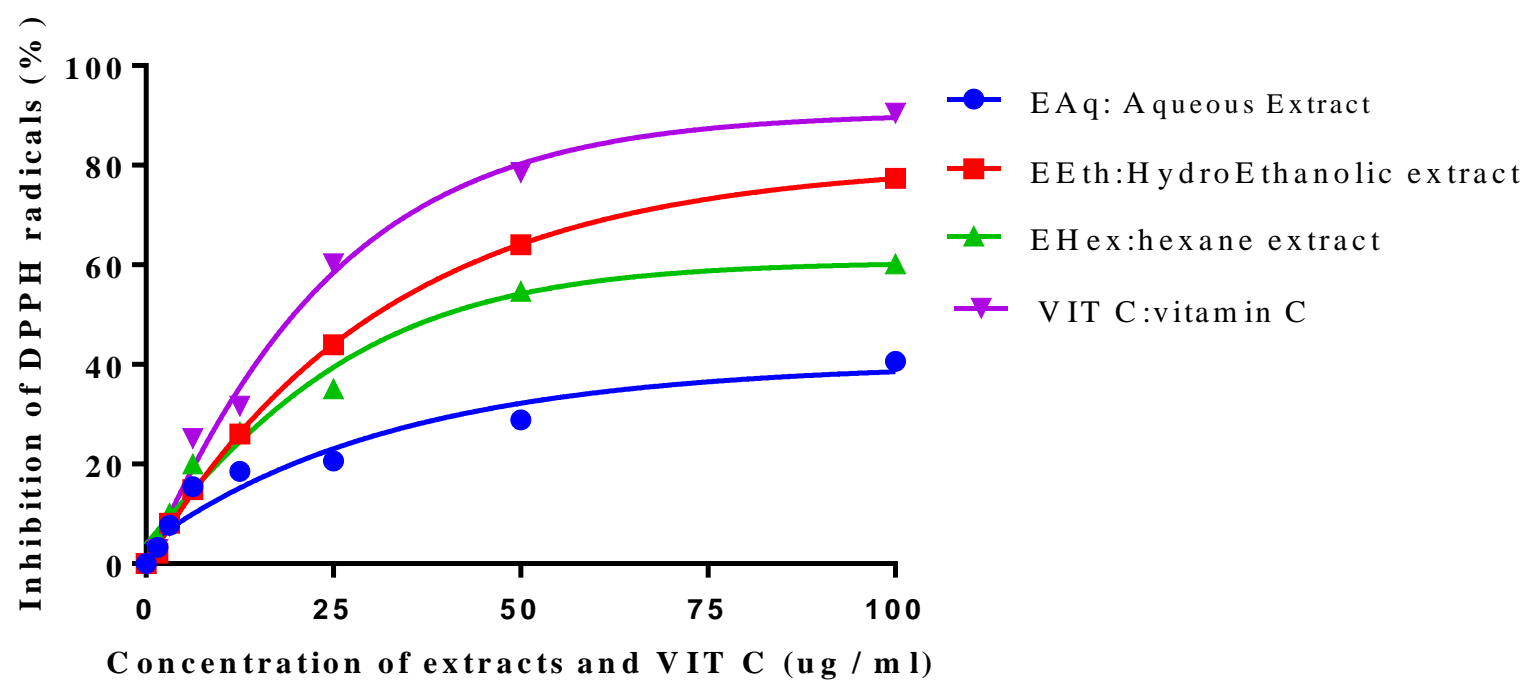


Graph.4 Evolution of the reducing power of extracts of Spathodea campanulata and BHT according to the concentration

\section{Reducing power measurement}

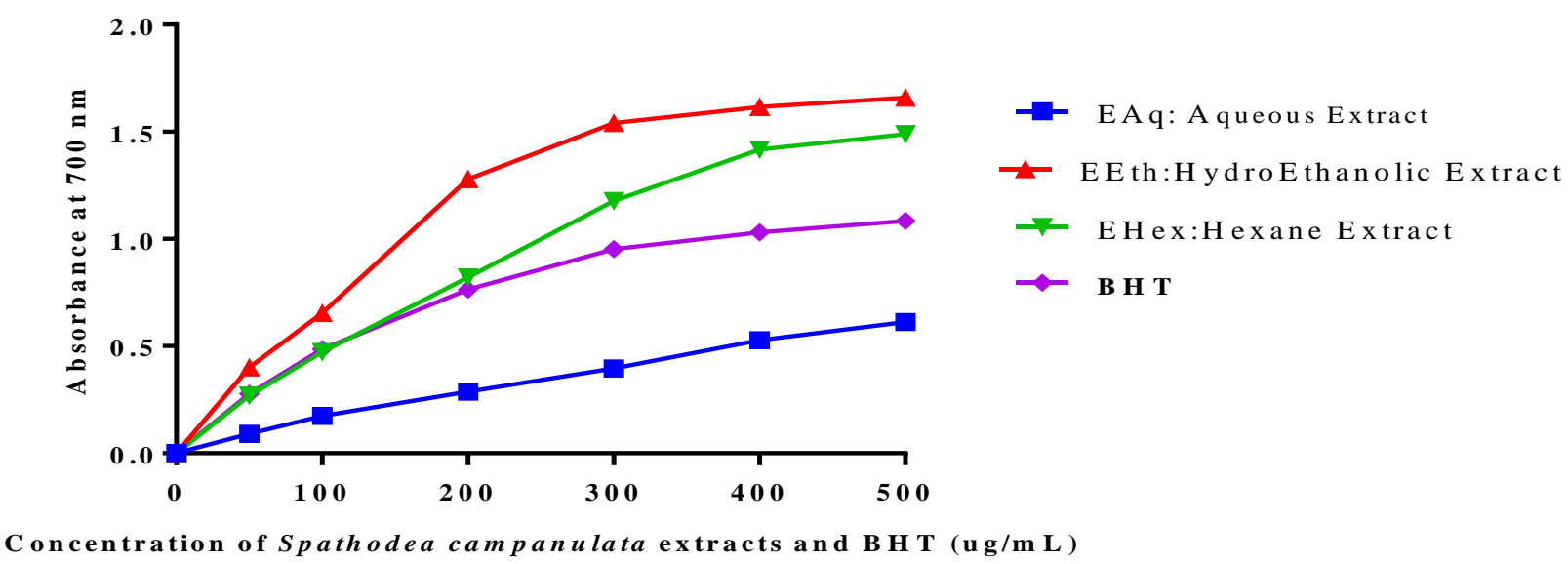

This reducing and anti-free radical power is based on the content of phenolic compounds in the bark of $S$. campanulata. Indeed, polyphenols are compounds possessing an antioxidant power due to their redox properties(Zeng et Wang, 2001). These properties make it possible to neutralize free radicals by donation of electrons or protons(Chen et Ho, 1995), to block the reaction chain of free radicals by transfer of hydrogen atoms (Meir et al., 1995). This antioxidant activity of polyphenols is often exploited in order to prevent and treat diseases linked to oxidative stress.

The study of the antioxidant activity of bark extracts from the species Spathodea campanulata according to the method of trapping the free radical DPPH and that of the reducing power of the ferric ion showed that the hydroethanolic extract has good antioxidant activity than aqueous and hexane extracts. However, this activity remains significantly lower than that of ascorbic acid and BHT used as reference molecules, but these are crude extracts containing a large number of different compounds. It is therefore very likely that they contain compounds which, once purified, may exhibit an activity comparable to that of the reference molecules. Likewise, the quantitative determination of the phenolic compounds by spectrophotometry of the dry extracts of the bark of $S$. campanulata showed the relative richness in phenolic constituents. These results have enabled us to deduce the recurrent use of this medicinal plant.

\section{Conflict of interests}

The authors claim that there is no conflict of interest.

\section{References}

Alonso M, Oliveros A, Calcagno P. 2007. Phenolics and condensed tannins of high altitude Pteridium arachnoideum in relation to sunlight exposure, elevation, and rain regime. Biochemical Systematics and Ecology; 35, 1-10.

Amusan O G, Adesogan, E K, Makinde. 1996. J M. Antimalarial active principles of Spathodea campanulata stem bark. 
Phytotherapy Research; 10 (8): 692-693.

Anusuya N, and Manian S. 2013. Antioxidant and free radical scavenging potential of different solvent extracts of Indigofera tinctoria L. leaves. International Journal of Pharmacy and Pharmaceutical Sciences; 1, 142-147.

Banerjee A, DE B. 2001. Anthocyanins in some flowers of West Bengal. Journal of Medicinal and Aromatic Plant Science; 23, 600-604.

Bruneton J. 1999. Pharmacognosie, phytochimie, plantes médicinales. Ed. Médicales internationales Editions Technique \& Documentation, Cachan, [S.1.] p. 647-673.

Chang C C, Yang M H, Wen H M, Chern J C. 2002. Estimation of total flavonoid content in propolis by two complementary colorimetric methods, Journal of Food and Drug Analysis; 10, 178-182

Chen C W et Ho C T. 1995. Antioxidant properties of polyphenols extracted from green tea and black tea. J Lipids ; 2, 3546.

Conde E, Cara C, Moure A, Ruiz E, Castro E, Dominguez H. 2009. Antioxidant activity of the phenolic compounds released by hydrothermal treatments of olive tree pruning. Food Chemistry; 114 (3): $806-812$

Djeridane A, Hamdi A, Bensania W, Cheifa K, Lakhdari I, Yousfi M. 2013. The in vitro evaluation of antioxidative activity, $\alpha$ glucosidase and $\alpha$-amylase enzyme inhibitory of natural phenolic extracts. Diabetes \& Metabolic Syndrome. Clinical Research \& Reviews; 9, 324331.

El-Hela A A. 2001a. Phenolics from Spathodea campanulata Beauv. Leaves. Al-Azhar Journal of Pharmaceutical Sciences; 27, 152-162.

El-Hela A A. 2001b. New iridoid glucoside from Spathodea campanulata Beauv. leaves. Al-Azhar Journal of Pharmaceutical Sciences; 27, 115-120

Fiorucci S. 2006. Activités biologiques de composés de la famille de flavonoïdes: approches par des méthodes de chimie quantique et de dynamique moléculaire. Thèse de doctorat. Nice, 211p.

Harrar A E N. 2012. Activités antioxydante et antimicrobienne d'extraits de Rhamnual aternus L. Mémoire de Magister, Université de Ferhat Abbas-Sétif (Algérie), $1 \mathrm{p}$

Huang, D, Ou B., Prior R. L. 2005. The chemistry behind antioxidant capacity assays. Journal Agriculture and Food Chemistry, 53, 1841-1856

Jardim M A, Mendonca L F R, Ferreira M M D. 2003.

http://www.mdic.gov.br/tecnologia/ revistas/artigos/200112pa/mariojardim.p df.

Katalinic, V, Milos, M, Kulisic, T, et Jukic, M. 2006. Screening of 70 medicinal plant extracts for antioxidant capacity and total phenols. Food Chemistry 94, 550557

Lagnika L.2005."Etude phytochimique et activité biologique de substances naturelles isolées de plantes béninoises" Thèse de doctorat, Université Louis Pasteur, Strasbourg, 249p.

Laguerre M, Leconte J, Villeneuve P. 2007. Evaluation of the ability of antioxidants to counteract lipid oxidation: existing methods, new trends and challenges. Prog. Lipid. Res.; 46(5):244-82

Mc Donald S, Prenzler P D, Antolovich M, Robards K. 2001. Phenolic content and antioxidant activity of olive extracts. Food Chemistry; 73, 73-84.

Meda A, Lamien C E, Romito M, Millogo J, Nacoulma O G. 2005. Determination of the total phenolic, flavonoid and proline contents in Burkina Fasan honey, as well as their radical scavenging activity. Food Chemistry; 91, 571-577.

Meir S, Kanner J, Akiri B, Hadar S P. 1995. Determination and involvement of aqueous reducing compounds in oxidative systems of various senescing leaves. J Agric FoodChemical; 43, 1813-1817 
Naczk M et Shahidi F. 2004. Extraction and analysis of phenolics in food. Journal of Chromatography A. 1054, 95-111.

Niyonzima G, Laekeman, G, Witvrouw M, Van Poel B, Pieters, L, Paper D. 1999. Hypoglycemic, anticomplement and anti-HIV activities of Spathodea campanulata stem bark. Phytomedicine; 6 (1): 45-49

Parejo I, Codina C, Petrakis C, Kefalas P. 2000. Evaluation of scavenging activity assessed by $\mathrm{Co}$ (II)/EDTA-induced luminal chemilunes-cence and DPPH (2,2-diphényl1-pycryl-hydrazyl) free radical assay. J Pharmacol Toxicol Method; 44, 507-512

Pedneault K, Leonhart S, Angenol L, Gosselin A, Ramputh A et Arnason J. 2001. Influence de la culture hydroponique de quelques plantes médicinales sur la croissance et la concentration en composés secondaires des organes végétaux. Texte de conférence, 5ème colloque sur les produits naturels d'origine végétale, Université Laval, Qc, Canada, 1-5

Rangasamy D, Asirvatham D, Muthusamy J, Rajamanickam K, Muthusamy P, Jeyaraman A. 2008. Preliminary Phytochemical Screening and Antimalarial Studies of Spathodea campanulatum $P$. Beauv Leaf Extracts. Ethnobotanical Leaflets; 12, 811-19

Singh J, Upadhyay A, Bahadur A, Singh B, Singh K, Rai M. 2006. Antioxidant phytochemicals in cabbage (Brassica oleracea L. var. capitata). Scientia Horticulturae; 108(3): 233-237.

Suhaj M. 2006. Spice antioxidants isolation and their antiradical activity: a review. Journal Food Composition and Analysis; 19, 531-537

Umenwa E, Emmanuel $\mathrm{O}$, Dorcas $\mathrm{O}$, Moronkola K, Adesanwo. 2017. Phytochemical and Antioxidant Assessments of Three Fractions from Methanol Extract of Spathodea campanulata Beauv. Leaves Journal of Complementary and Alternative Medical Research; 3(3): 1-10

Yildirim A, Mavi A, Kara A. 2001. Determination of antioxidant and antimicrobial activities of Rumex crispus L. extracts. Journal of Agricultural and Food Chemistry; 49, 4083- 4089.

Zeng W et Wang SY. 2001. Antioxidant activity and phenolic compounds in selected herbs. Journal of Agriculture and Food Chemistry; 49, 5165-5170.

Zhao X, Iwamoto T, Carey E. 2007. Antioxidant capacity of leafy vegetables as affected by high tunnel environment, fertilisation and growth stage. Journal of the Science of Food and Agriculture; 87, 2692-2699.

Zirihi G, Kra A K, Guede-Guina F. 2003. Évaluation de l'activité antifongique de Microglossa pyrifolia (Lamarck) $\mathrm{O}$. Kantze (Astéracée) «PYMI » sur la croissance in vitro de Candida albicans, Revue de Médecine et pharmacie Afrique; 17, 11-18.

\section{How to cite this article:}

Koulai Diane, Yeo Sounta Oumar, Doumbia Idrissa, Yapi Houphouet Felix, N'guessan Jean David and Djaman Allico Joseph. 2021. Evaluation of the Antioxidant Activity and Dosage of Polyphenols in Aqueous, Hydroethanolic and Hexane Extracts of the Bark of Spathodea campanulata P. Beauv. (Bignoniaceae). Int.J.Curr.Microbiol.App.Sci. 10(07): 154-163. doi: https://doi.org/10.20546/ijcmas.2021.1007.018 